\title{
Determination of Scale Effects on Mechanical Properties of Berea Sandstone
}

\author{
Hui Li $\mathbb{D}^{1}{ }^{1}$ Kaoping Song $\mathbb{D}^{1}{ }^{1}$ Mingguang Tang, ${ }^{2}$ Ming Qin, ${ }^{3}$ Zhenping Liu, ${ }^{3}$ Ming Qu, \\ Ben $\mathrm{Li}^{1}{ }^{1}$ and Yan $\mathrm{Li}^{4}$ \\ ${ }^{1}$ China University of Petroleum, Beijing, China \\ ${ }^{2}$ Zhanjiang Branch of CNOOC Ltd., Zhanjiang, China \\ ${ }^{3}$ Research Institute of Petroleum Exploration and Development, Xinjiang Oilfield, Kelamayi, China \\ ${ }^{4}$ Institute of Mineral Resources Research, China Metallurgical Geology Bureau, Beijing, China
}

Correspondence should be addressed to Hui Li; 20234914@qq.com and Kaoping Song; 2307752783@qq.com

Received 26 November 2020; Revised 4 January 2021; Accepted 24 January 2021; Published 9 February 2021

Academic Editor: Shiyuan Zhan

Copyright (C) 2021 Hui Li et al. This is an open access article distributed under the Creative Commons Attribution License, which permits unrestricted use, distribution, and reproduction in any medium, provided the original work is properly cited.

The key rock mechanical parameters are strength, elastic modulus, Poisson's ratio, etc., which are important in reservoir development. The accurate determination of reservoir's mechanical properties is critical to reduce drilling risk and maximize well productivity. Precisely estimating rock mechanical properties is important in drilling and well completion design, as well as crucial for hydraulic fracturing. Rocks are heterogeneous and anisotropic materials. The mechanical properties vary not only with rock types but also with measurement methods, sample geometric dimensions (sample length to diameter ratio and size), and other factors. To investigate sample scale effects on rock mechanical behaviors, unconfined compression tests were conducted on 41 different geometric dimensions of Berea sandstones; unconfined compressive strength (UCS), Young's modulus $(E)$, Poisson's ratio $(v)$, bulk modulus $(K)$, and shear modulus $(G)$ were obtained and compared. The results indicate that sample geometry can significantly affect rock mechanical properties: (1) UCS decreases with the increase of length to diameter ratio (LDR), and the UCS standardize factor is between 0.71 and 1.17 , which means $-30 \%$ to $+20 \%$ variation of UCS with LDR changing from 1 to 6.7. The test results show UCS exhibits positive relationship with sample size. (2) Young's modulus slightly increases with LDR increases, while Poisson's ratio decreases with the increase of LDR. For the tested Berea sandstones, Poisson's ratio standardizing factor is between 0.57 and 1.11. (3) Bulk modulus of Berea sandstone samples decreases with the increase of LDR, while shear modulus increases with LDR increases. Both bulk modulus and shear modulus increase with the increase of sample size. (4) The principal failure modes were analyzed. The failure modes of the tested Berea sandstones are axial splitting and shear failure. Stocky samples $(\mathrm{LDR}<2)$ tend to go axial splitting, while slender samples $(\mathrm{LDR}>2)$ tend to show shear failure.

\section{Introduction}

Rock mechanical properties introduced terms such as strength, elastic modulus, and Poisson's ratio, which are important in drilling, well completion, and hydraulic fracturing [1-7]. Strength and elastic properties are important parameters in drilling, evaluations, completion, and production forecasting for conventional and unconventional resources, which are key inputs in geomechanical models (Prasad 2019). Rocks are heterogeneous materials. Therefore, rock mechanical properties vary not only with rock types but also with sample geometry. In pure mechanics, a true material property should not vary with sample geometric dimensions. Thus, material properties will remain unchanged at any range of scales only if the material itself remains purely homogeneous. As a matter of fact, rocks are heterogeneous, and the mechanical properties obtained from different geometry of core sample are different [8]. Generally, rock mechanical properties show a dependency on LDR and sample size [9-11], which is defined as scale effects. In fact, there is no contradiction between rock mechanics and pure mechanics. The basic concepts of mechanics have to be kept, and some 
practical adjustments have to be adopted for rock engineering problems. Hence, whatever the geometry of the samples used in the test, the test results for determining the material mechanical properties have to be changed accordingly. Usually, rock sample geometry can influence rock mechanical behaviors. One reason is that the friction between the sample and the load platen may influence the test results [12]. In addition, long samples may lead to bending, while short samples could cause shear fracture plane during unconfined and confined tests [13]. Therefore, it is necessary to qualify and integrate the scale effects to make sure the values are reliable. According to the test results of Forbes et al. [14], the suitable correction for unconfined compressive strength (UCS) was well established, which would be applied for apparent high strength in UCS and CCS.

The scale effects on rock mechanical properties have been well investigated by many researchers. John [15] conducted uniaxial compression tests on dry sandstones and concluded that the strength was almost unchanged when the sample's length to diameter ratio equals to 2 or greater. But when LDR was less than 2 , the strength apparently decreased with the increase of LDR. Thuro et al. [11] conducted an unconfined compression test on kersantite and limestone to study the scale effects on rock mechanical properties and concluded that scale effects on elastic modulus and tensile strength were significant, while the influence on UCS was much lower. Mogi $[16,17]$ conducted unconfined compression tests on different rock types with different LDR and concluded that UCS decreased with the increase of LDR. According to the research of Dirige and Archibald [18], UCS of granodiorite and granite moderately decreased with the increase of LDR, while Young's modulus was almost unchanged. Tuncay and Hasancebi [19] concluded that high UCS values were obtained at LDR less than 2, a very slight difference in values between 2 and 2.5, and they were remaining effectively constant when LDR was larger than 2.5. Prasad et al. [20] concluded that a larger correction was needed on smaller L/D core plugs, and the effect of confining pressures continues to decrease until the rock behaves plastically or shows the barreling effect. The effects of sample size on rock mechanical behaviors were also well investigated. According to the research conducted by Hoek and Brown [21], the diameter approximated to $50 \mathrm{~mm}$ was preferred; Hawkins [22] got a similar conclusion. ASTM D2938 recommended the diameter of the core should be at least six to ten times that of the largest grain or fragment of the rock. According to the results of Thuro et al. [11], sample diameter had a marginal effect on UCS of limestone and granite and had a little effect on elastic modulus and tensile strength of limestone. Masoumi and Douglas [23] concluded that UCS first increased then slightly decreased with the increase of sample size, and the boundary between ascending and descending zones was variable, depending on the rock type and most likely crystal or grain size. Forbes et al. [14] conducted both axial and diametric point load tests of Gosford sandstone and found that the point load strength index varies increasingly with sample diameter for all investigated samples at different length to diameter ratios. Their experimental results also

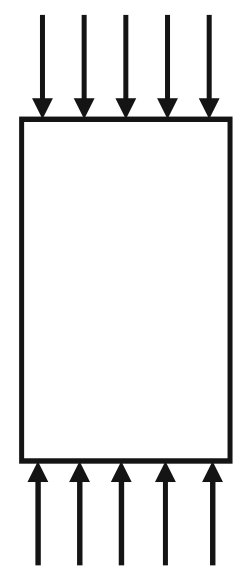

FIGURE 1: UCS test setup schematic.

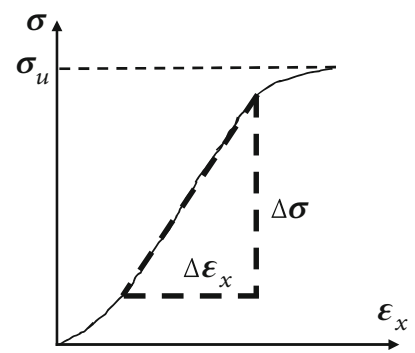

FIGURE 2: Stress-strain curve of the UCS test.

demonstrated that as the sample diameter increased, the point load strength index decreased.

In this work, uniaxial compression tests were conducted on 41 different dimensions of Berea sandstone samples to systematically study the scale effects on mechanical properties of Berea sandstones. Correction equations and standardizing factors were obtained to minimize the scale effects and get more reliable rock mechanical properties. Meanwhile, failure modes of the tested samples were studied.

\section{Experimental Parameters and Sample Description}

2.1. Experimental Parameters. The mechanical parameters studied in this work mainly include unconfined compressive strength (UCS), Young's modulus (E), Poisson's ratio $(v)$, bulk modulus $(K)$, and shear modulus $(G)$. In a uniaxial compression test, a right circular cylinder of a rock is compressed between two parallel rigid plates (Figure 1). The axial stress is the controlled, independent variable, while the axial strain is the dependent variable. The strain can be measured by a strain gauge. UCS is the maximum stress that the rock can sustain under a uniaxial compression test. The most useful description of the mechanical behavior of rock is the stress-strain curve, from which UCS and Young modulus can be determined (Figure 2). Bulk modulus and shear modulus are the parameters related to Young's modulus and Poisson's 
TABLE 1: Berea sandstone samples in the uniaxial compression tests.

\begin{tabular}{|c|c|c|c|c|c|c|c|c|}
\hline \multirow{2}{*}{ LDR } & & \multicolumn{7}{|c|}{$D$ (in) } \\
\hline & & 0.5 & 0.75 & 1 & 1.5 & 2 & 3 & 4 \\
\hline \multirow{11}{*}{$L$ (in) } & 0.75 & 1.5 & 1 & & & & & \\
\hline & 1 & 2 & 1.3 & 1 & & & & \\
\hline & 1.2 & 2.4 & 1.6 & 1.2 & & & & \\
\hline & 1.5 & 3 & 2 & 1.5 & 1 & & & \\
\hline & 1.8 & & 2.4 & 1.8 & 1.2 & & & \\
\hline & 2 & & 2.7 & 2 & 1.3 & 1 & & \\
\hline & 3 & & & 3 & 2 & 1.5 & 1 & \\
\hline & 4 & & & 4 & 2.7 & 2 & 1.3 & 1 \\
\hline & 6 & & & 6 & 4 & 3 & 2 & 1.5 \\
\hline & 8 & & & & 5.3 & 4 & 2.7 & 2 \\
\hline & 10 & & & & 6.7 & 5 & 3.3 & 2.5 \\
\hline
\end{tabular}

ratio. The specific calculation of these mechanical parameters is as follows:

$$
\begin{gathered}
\sigma_{u}=\frac{P}{A}, \\
E=\frac{\Delta \sigma}{\Delta \varepsilon_{x}}, \\
v=\left|\frac{\varepsilon_{y}}{\varepsilon_{x}}\right|, \\
K=\frac{E}{3(1-2 v)}, \\
G=\frac{E}{2(1+v)},
\end{gathered}
$$

where $\sigma_{u}$ is the uniaxial compressive strength (UCS), $P$ is failure load and $A$ is the cross-sectional area, $\Delta \sigma$ is the change in stress, $\Delta \varepsilon_{x}$ is the change in longitudinal strain, $\varepsilon_{y}$ is the lateral strain, and $\varepsilon_{x}$ is the longitudinal strain.

2.2. Sample Description. Berea sandstone is a Mississippian terrestrial sandstone. The sandstone samples used in this research are finer-grained and well-sorted outcrop Berea sandstones. X-ray diffraction was conducted to analyze the mineralogy of Berea sandstone which shows $91 \%$ quartz, $2 \%$ clay, $3 \%$ feldspar, $2 \%$ plagioclase, and $2 \%$ chlorite. There are 41 different geometric dimensions of Berea sandstone samples that were tested with sample diameters $(D)$ ranging from 0.5 inch to 4 inches, sample length $(L)$ from 0.75 inch to 10 inches, and LDR ranging from 1 to 6.7. The detailed sample geometric dimensions are listed in Table 1.

\section{Experimental Procedures}

The experimental setup mainly consists of a material testing system, MTS-810 (Figure 3), strain gauges, and a data acquisition system. The test procedures are described as follows: (1) prepare 41 Berea sandstone core samples. Then, attach the strain gauge to the core sample. For a

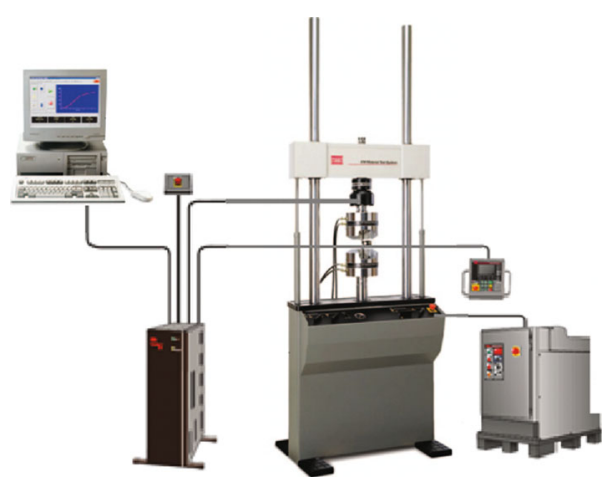

Figure 3: The MTS-810 material testing system.

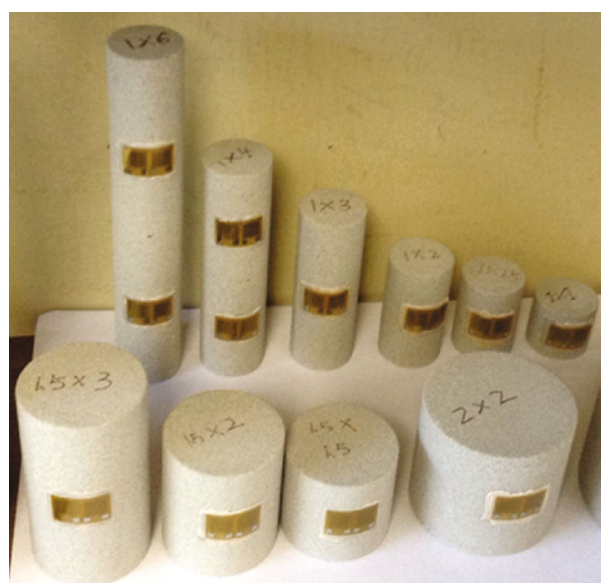

FIGURE 4: Core samples with the strain gauges attached.

long sample, two strain gauges were attached and the average strain was used in the calculation (Figure 4); (2) put the sample in the middle of the material testing system. Turn on the computer and set the program for testing; (3) start running the programs, and the loading force will be added to the sample gradually. When hearing breaking sound, stop the programs to end the test; (4) acquire the data and calculate UCS, $E, v, K$, and $G$ based on Equations (1)-(5).

\section{Experimental Results and Analysis}

The test results of Berea sandstone samples are illustrated in Table 2. The mechanical parameters were calculated according to Equations (1)-(5).

4.1. LDR and Size Effects on UCS. 41 Berea sandstone samples used in this research can be divided into 17 different LDR (1, $1.2,1.3,1.5,1.6,1.8,2,2.4,2.5,2.7,3,3.3,4,5,5.3,6$, and 7 ), see Table 3. To investigate the 17 different LDR effects, normalization process was used. Equation (6) is the normalized equation used for evaluating the LDR effect on UCS.

$$
\mathrm{UCSN}_{j}^{i}=\frac{\mathrm{UCS}_{j}^{i}}{\mathrm{UCS}_{2}^{i}}
$$


TABLE 2: Test results of 41 Berea sandstone samples.

\begin{tabular}{|c|c|c|c|c|c|c|}
\hline $\begin{array}{l}D \\
\text { (in) }\end{array}$ & $\begin{array}{c}L \\
\text { (in) }\end{array}$ & $\begin{array}{l}\text { UCS } \\
(\mathrm{MPa})\end{array}$ & $\begin{array}{c}E \\
(\mathrm{GPa})\end{array}$ & $\begin{array}{l}\text { Poisson's } \\
\text { ratio }\end{array}$ & $\begin{array}{c}K \\
(\mathrm{GPa})\end{array}$ & $\begin{array}{c}G \\
(\mathrm{GPa})\end{array}$ \\
\hline 0.5 & 0.75 & 30.2 & 8.2 & 0.406 & 14.5 & 2.9 \\
\hline 0.5 & 1 & 28.3 & 8.2 & 0.336 & 8.3 & 3.1 \\
\hline 0.5 & 1.2 & 33.7 & 9.8 & 0.328 & 9.5 & 3.7 \\
\hline 0.5 & 1.5 & 21.2 & 9.4 & 0.261 & 6.6 & 3.7 \\
\hline 0.75 & 0.75 & 33.6 & 7.9 & 0.315 & 7.1 & 3.0 \\
\hline 0.75 & 1 & 34.1 & 7.3 & 0.372 & 9.5 & 2.7 \\
\hline 0.75 & 1.2 & 33.6 & 8.3 & 0.367 & 10.4 & 3.0 \\
\hline 0.75 & 1.5 & 31.8 & 8.7 & 0.331 & 8.6 & 3.3 \\
\hline 0.75 & 1.8 & 28.8 & 8.2 & 0.286 & 6.4 & 3.2 \\
\hline 0.75 & 2 & 34.0 & 9.2 & 0.314 & 8.2 & 3.5 \\
\hline 1 & 1 & 43.9 & 8.6 & 0.326 & 8.2 & 3.2 \\
\hline 1 & 1.2 & 36.2 & 8.1 & 0.334 & 8.1 & 3.0 \\
\hline 1 & 1.5 & 33.6 & 12.8 & 0.399 & 21.1 & 4.6 \\
\hline 1 & 1.8 & 33.5 & 9.3 & 0.362 & 11.2 & 3.4 \\
\hline 1 & 2 & 33.2 & 9.5 & 0.376 & 12.8 & 3.5 \\
\hline 1 & 3 & 34.0 & 10.7 & 0.224 & 6.5 & 4.4 \\
\hline 1 & 4 & 30.2 & 9.3 & 0.378 & 12.7 & 3.4 \\
\hline 1 & 6 & 24.1 & 11.7 & 0.308 & 10.2 & 4.5 \\
\hline 1.5 & 1.5 & 43.2 & 10.2 & 0.318 & 9.3 & 3.9 \\
\hline 1.5 & 1.8 & 39.4 & 10.2 & 0.328 & 9.9 & 3.8 \\
\hline 1.5 & 2 & 43.4 & 10.2 & 0.376 & 13.7 & 3.7 \\
\hline 1.5 & 3 & 43.5 & 9.7 & 0.389 & 14.6 & 3.5 \\
\hline 1.5 & 4 & 38.3 & 12.0 & 0.389 & 18.0 & 4.3 \\
\hline 1.5 & 6 & 41.3 & 12.2 & 0.269 & 8.8 & 4.8 \\
\hline 1.5 & 8 & 33.6 & 10.4 & 0.231 & 6.4 & 4.2 \\
\hline 1.5 & 10 & 30.8 & 11.1 & 0.222 & 6.7 & 4.5 \\
\hline 2 & 2 & 51.3 & 11.6 & 0.326 & 11.1 & 4.4 \\
\hline 2 & 3 & 39.5 & 11.9 & 0.367 & 14.9 & 4.4 \\
\hline 2 & 4 & 39.7 & 10.1 & 0.365 & 12.5 & 3.7 \\
\hline 2 & 6 & 37.8 & 11.7 & 0.378 & 16.0 & 4.2 \\
\hline 2 & 8 & 36.0 & 14.0 & 0.245 & 9.2 & 5.6 \\
\hline 2 & 10 & 28.8 & 11.6 & 0.322 & 10.9 & 4.4 \\
\hline 3 & 3 & 49.7 & 13.2 & 0.324 & 12.5 & 5.0 \\
\hline 3 & 4 & 45.8 & 13.3 & 0.357 & 15.5 & 4.9 \\
\hline 3 & 6 & 42.6 & 13.0 & 0.351 & 14.5 & 4.8 \\
\hline 3 & 8 & 43.1 & 12.3 & 0.208 & 7.0 & 5.1 \\
\hline 3 & 10 & 38.7 & 12.6 & 0.375 & 16.8 & 4.6 \\
\hline 4 & 4 & 56.2 & 14.9 & 0.332 & 14.8 & 5.6 \\
\hline 4 & 6 & 45.8 & 12.1 & 0.355 & 13.9 & 4.5 \\
\hline 4 & 8 & 46.5 & 15.3 & 0.364 & 18.8 & 5.6 \\
\hline 4 & 10 & 41.8 & 15.8 & 0.368 & 19.9 & 5.8 \\
\hline
\end{tabular}

TABLE 3: Effects of LDR on UCS of Berea sandstone samples.

\begin{tabular}{|c|c|c|c|c|c|}
\hline LDR & $D$ (in) & $L$ (in) & UCS (MPa) & UCSN & $\mathrm{SF}_{\mathrm{UCS}}$ \\
\hline 1 & 0.75 & 0.75 & 33.6 & 1.06 & \multirow{6}{*}{1.17} \\
\hline 1 & 1 & 1 & 43.9 & 1.32 & \\
\hline 1 & 1.5 & 1.5 & 43.2 & 0.99 & \\
\hline 1 & 2 & 2 & 51.3 & 1.29 & \\
\hline 1 & 3 & 3 & 49.7 & 1.17 & \\
\hline 1 & 4 & 4 & 56.2 & 1.21 & \\
\hline 1.2 & 1 & 1.2 & 36.2 & 1.09 & \multirow{2}{*}{1.00} \\
\hline 1.2 & 1.5 & 1.8 & 39.4 & 0.91 & \\
\hline 1.3 & 0.75 & 1 & 34.1 & 1.07 & \multirow{3}{*}{1.05} \\
\hline 1.3 & 1.5 & 2 & 43.4 & 1.00 & \\
\hline 1.3 & 3 & 4 & 45.8 & 1.08 & \\
\hline 1.5 & 0.5 & 0.75 & 30.2 & 1.07 & \multirow{4}{*}{1.01} \\
\hline 1.5 & 1 & 1.5 & 33.6 & 1.01 & \\
\hline 1.5 & 2 & 3 & 39.5 & 0.99 & \\
\hline 1.5 & 4 & 6 & 45.8 & 0.98 & \\
\hline 1.6 & 0.75 & 1.2 & 33.6 & 1.06 & 1.06 \\
\hline 1.8 & 1 & 1.8 & 33.5 & 1.01 & 1.01 \\
\hline 2 & 0.5 & 1 & 28.3 & 1 & \multirow{7}{*}{1} \\
\hline 2 & 0.75 & 1.5 & 31.8 & 1 & \\
\hline 2 & 1 & 2 & 33.2 & 1 & \\
\hline 2 & 1.5 & 3 & 43.5 & 1 & \\
\hline 2 & 2 & 4 & 39.7 & 1 & \\
\hline 2 & 3 & 6 & 42.6 & 1 & \\
\hline 2 & 4 & 8 & 46.5 & 1 & \\
\hline 2.4 & 0.5 & 1.2 & 33.7 & 1.19 & \multirow{2}{*}{1.05} \\
\hline 2.4 & 0.75 & 1.8 & 28.8 & 0.91 & \\
\hline 2.5 & 4 & 10 & 41.8 & 0.90 & 0.90 \\
\hline 2.7 & 0.75 & 2 & 34 & 1.07 & \multirow{3}{*}{0.99} \\
\hline 2.7 & 1.5 & 4 & 38.3 & 0.88 & \\
\hline 2.7 & 3 & 8 & 43.1 & 1.01 & \\
\hline 3 & 0.5 & 1.5 & 21.2 & 0.75 & \multirow{3}{*}{0.91} \\
\hline 3 & 1 & 3 & 34 & 1.02 & \\
\hline 3 & 2 & 6 & 37.8 & 0.95 & \\
\hline 3.3 & 3 & 10 & 38.7 & 0.91 & 0.91 \\
\hline 4 & 1 & 4 & 30.2 & 0.91 & \multirow{3}{*}{0.92} \\
\hline 4 & 1.5 & 6 & 41.3 & 0.95 & \\
\hline 4 & 2 & 8 & 36 & 0.91 & \\
\hline 5 & 2 & 10 & 28.8 & 0.73 & 0.73 \\
\hline 5.3 & 1.5 & 8 & 33.6 & 0.77 & 0.77 \\
\hline 6 & 1 & 6 & 24.1 & 0.73 & 0.73 \\
\hline 6.7 & 1.5 & 10 & 30.8 & 0.71 & 0.71 \\
\hline
\end{tabular}




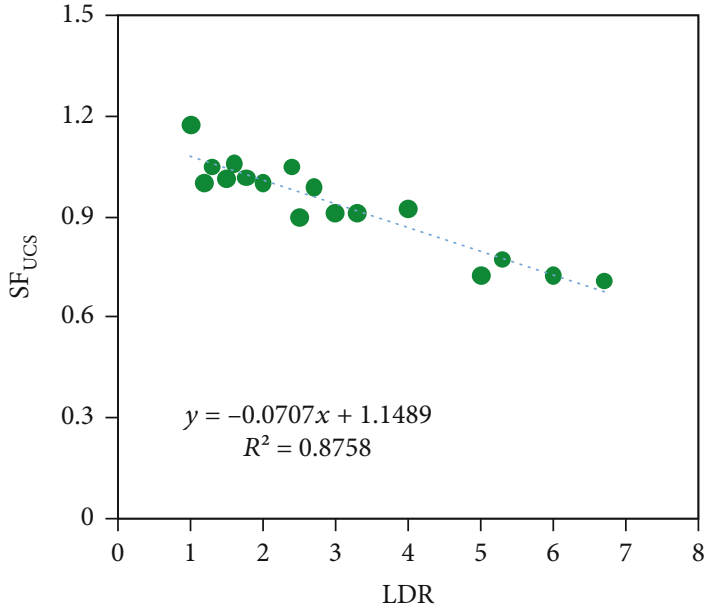

FIGURE 5: The relationship of LDR and $\mathrm{SF}_{\mathrm{UCS}}$.

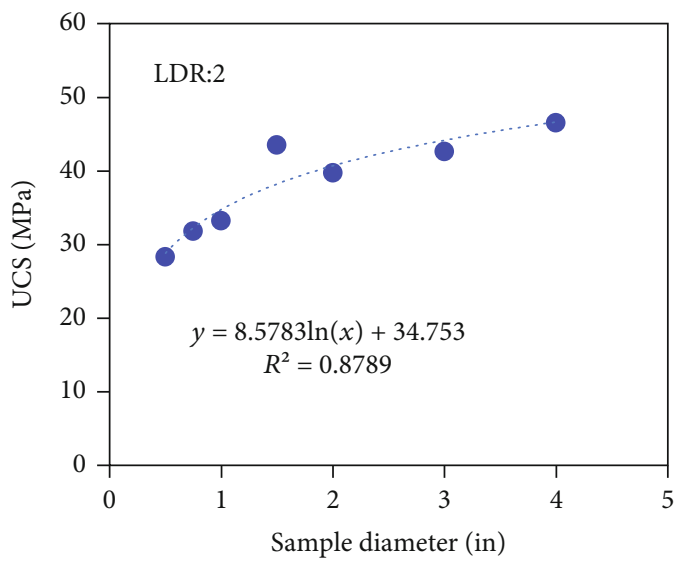

FIgURE 6: Effect of sample size on UCS.

where $\mathrm{UCSN}_{j}^{i}$ is defined as the normalized uniaxial compressive strength indicator of the sample with diameter $i$ and $\operatorname{LDR} j \cdot \mathrm{UCS}_{j}^{i}$ is the UCS of the sample with diameter $i$ and LDR $j . \mathrm{UCS}_{2}^{i}$ is the UCS of the sample with diameter $i$ and LDR at 2. The reason why LDR at 2 was chosen as the reference UCS is based on the ASTM standard (the desirable specimen length to diameter ratio of ASTM standard is 2 to 2.5). In order to get more clear results of the LDR on UCS, Equation (7) was used to calculate the average value of normalized compressive strength indicator, which is defined as UCS standardizing factor.

$$
\mathrm{SF}_{\mathrm{UCS} j}=\frac{1}{n} \sum_{i=1}^{n} \mathrm{UCS}_{j}^{i} \text {, }
$$

where $\mathrm{SF}_{\mathrm{UCS} j}$ is the UCS standardizing factor with LDR $j . n$ is the number of the tested samples with the same LDR. Table 3 provides a summary of the results of UCS for the tested 41 Berea sandstone samples. Figure 5 is the relationship of UCS standardizing factor and LDR,
TABLE 4: Effects of LDR on Young's modulus of Berea sandstones.

\begin{tabular}{|c|c|c|c|c|c|}
\hline LDR & $D$ (in) & $L$ (in) & $E(\mathrm{GPa})$ & $\mathrm{EN}$ & $\mathrm{SF}_{E}$ \\
\hline 1 & 0.75 & 0.75 & 7.9 & 0.91 & \multirow{6}{*}{1} \\
\hline 1 & 1 & 1 & 8.6 & 0.91 & \\
\hline 1 & 1.5 & 1.5 & 10.2 & 1.05 & \\
\hline 1 & 2 & 2 & 11.6 & 1.15 & \\
\hline 1 & 3 & 3 & 13.2 & 1.02 & \\
\hline 1 & 4 & 4 & 14.9 & 0.97 & \\
\hline 1.2 & 1 & 1.2 & 8.1 & 0.85 & \multirow{2}{*}{0.95} \\
\hline 1.2 & 1.5 & 1.8 & 10.2 & 1.05 & \\
\hline 1.3 & 0.75 & 1 & 7.3 & 0.84 & \multirow{3}{*}{0.97} \\
\hline 1.3 & 1.5 & 2 & 10.2 & 1.05 & \\
\hline 1.3 & 3 & 4 & 13.3 & 1.02 & \\
\hline 1.5 & 0.5 & 0.75 & 8.2 & 1.00 & \multirow{4}{*}{1.08} \\
\hline 1.5 & 1 & 1.5 & 12.8 & 1.35 & \\
\hline 1.5 & 2 & 3 & 11.9 & 1.18 & \\
\hline 1.5 & 4 & 6 & 12.1 & 0.79 & \\
\hline 1.6 & 0.75 & 1.2 & 8.3 & 0.95 & 0.95 \\
\hline 1.8 & 1 & 1.8 & 9.3 & 0.98 & 0.98 \\
\hline 2 & 0.5 & 1 & 8.2 & 1 & \multirow{7}{*}{1} \\
\hline 2 & 0.75 & 1.5 & 8.7 & 1 & \\
\hline 2 & 1 & 2 & 9.5 & 1 & \\
\hline 2 & 1.5 & 3 & 9.7 & 1 & \\
\hline 2 & 2 & 4 & 10.1 & 1 & \\
\hline 2 & 3 & 6 & 13 & 1 & \\
\hline 2 & 4 & 8 & 15.3 & 1 & \\
\hline 2.4 & 0.5 & 1.2 & 9.8 & 1.20 & \multirow{2}{*}{1.07} \\
\hline 2.4 & 0.75 & 1.8 & 8.2 & 0.94 & \\
\hline 2.5 & 4 & 10 & 15.8 & 1.03 & 1.03 \\
\hline 2.7 & 0.75 & 2 & 9.2 & 1.06 & \multirow{3}{*}{1.08} \\
\hline 2.7 & 1.5 & 4 & 12 & 1.24 & \\
\hline 2.7 & 3 & 8 & 12.3 & 0.95 & \\
\hline 3 & 0.5 & 1.5 & 9.4 & 1.15 & \multirow{3}{*}{1.14} \\
\hline 3 & 1 & 3 & 10.7 & 1.13 & \\
\hline 3 & 2 & 6 & 11.7 & 1.16 & \\
\hline 3.3 & 3 & 10 & 12.6 & 0.97 & 0.97 \\
\hline 4 & 1 & 4 & 9.3 & 0.98 & \multirow{3}{*}{1.21} \\
\hline 4 & 1.5 & 6 & 12.2 & 1.26 & \\
\hline 4 & 2 & 8 & 14 & 1.39 & \\
\hline 5 & 2 & 10 & 11.6 & 1.15 & 1.15 \\
\hline 5.3 & 1.5 & 8 & 10.4 & 1.07 & 1.07 \\
\hline 6 & 1 & 6 & 11.7 & 1.23 & 1.23 \\
\hline 6.7 & 1.5 & 10 & 11.1 & 1.14 & 1.14 \\
\hline
\end{tabular}


TABLE 5: Correlation Equations of Elastic Parameters and LDR.

\begin{tabular}{lcc}
\hline Normalized elastic parameters & Standardizing factor & Correction equation \\
\hline $\mathrm{EN}_{j}^{i}=\frac{E_{j}^{i}}{E_{2}^{i}}$ & $\mathrm{SF}_{E j}=\frac{1}{n} \sum_{i=1}^{n} \mathrm{EN}_{j}^{i}$ & $\mathrm{SF}_{E}=0.114 \ln (\mathrm{LDR})+0.952$ \\
$v N_{j}^{i}=\frac{v_{j}^{i}}{v_{2}^{i}}$ & $\mathrm{SF}_{v j}=\frac{1}{n} \sum_{i=1}^{n} v N_{j}^{i}$ & $\mathrm{SF}_{v}=-0.17 \times \ln (\mathrm{LDR})+1.06$ \\
$\mathrm{KN}_{j}^{i}=\frac{K_{j}^{i}}{K_{2}^{i}}$ & $\mathrm{SF}_{K j}=\frac{1}{n} \sum_{i=1}^{n} \mathrm{KN}_{j}^{i}$ & $\mathrm{SF}_{K}=1.17 e^{-0.103 x}$ \\
$\mathrm{GN}_{j}^{i}=\frac{G_{j}^{i}}{G_{2}^{i}}$ & $\mathrm{SF}_{G j}=\frac{1}{n} \sum_{i=1}^{n} \mathrm{GN}_{j}^{i}$ & $\mathrm{SF}_{G}=0.176 \ln (\mathrm{LDR})+0.932$ \\
\hline
\end{tabular}

showing $\mathrm{SF}_{\mathrm{UCS}}$ of Berea Sandstone cores decreases as LDR increases, which illustrates that UCS decreases with LDR increases. This is probably caused by bending effects. It is easier for a rock sample to bend if it is long. In UCS tests, the force was added at both ends of the sample, so it is relatively easier to break down if a sample is with a larger LDR. Equation (8) is the correction equation of $\mathrm{S}$ $\mathrm{F}_{\mathrm{UCS}}$ and LDR for Berea sandstones, which indicates the negative linear relationships between $\mathrm{SF}_{\mathrm{UCS}}$ and LDR; the correlation coefficient is 0.88 , which is relatively high. S $\mathrm{F}_{\mathrm{UCS}}$ is between 0.71 and 1.17 , which means $-30 \%$ to $+20 \%$ variation of UCS with LDR changing from 1 to 6.7 .

$$
\mathrm{SF}_{\mathrm{UCS}}=-0.071(\mathrm{LDR})+1.149
$$

From Table 3, we can observe that UCS increases with sample diameter increases at the same LDR, except for LDR at 2.4 and 4 . Because there are only 2 sample sizes at LDR of 2.4 and only 3 sample sizes at LDR of 4 , these data are not representative. Figure 6 shows the UCS increases with sample size increases with LDR at 2, which is representative because there are 7 different sample sizes. From Figure 6, we can observe the positive relationship with UCS and sample diameter.

4.2. LDR and Size Effects on E, Poisson's Ratio, K, and G. Young's modulus is a parameter used to describe the stiffness of elastic materials. It is the ratio of the stress to the strain along the same axis in the range of stress in which Hooke's law holds $[24,25]$. Table 4 is the summary of Young's modulus and the calculated EN and $\mathrm{SF}_{E}$ of the tested Berea sandstone samples. Table 5 shows the correlation equation of Young's modulus standardizing factor $\left(\mathrm{SF}_{E}\right)$ and LDR with correlation coefficient which is 0.57 . According to the normalized results of this research, Young's modulus of Berea sandstone samples would slightly increase with LDR increases, as shown in Figure 7. Figure 8 shows Young's modulus increases with the increase of sample diameter with LDR at 2, meaning Young's modulus increases with sample size increases.

$E_{j}^{i}$ is Young's modulus of the sample with diameter $i$ and LDR $j ; E_{2}^{i}$ is Young's modulus of the sample with diameter $i$

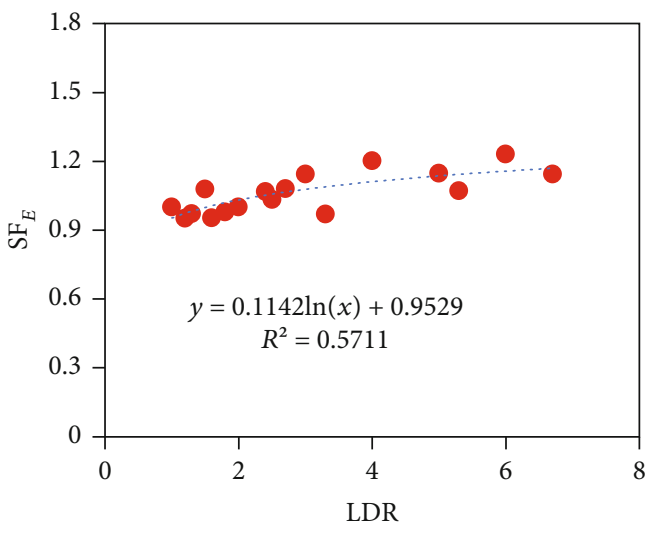

FIGURE 7: The relationship of LDR and $\mathrm{SF}_{E}$.

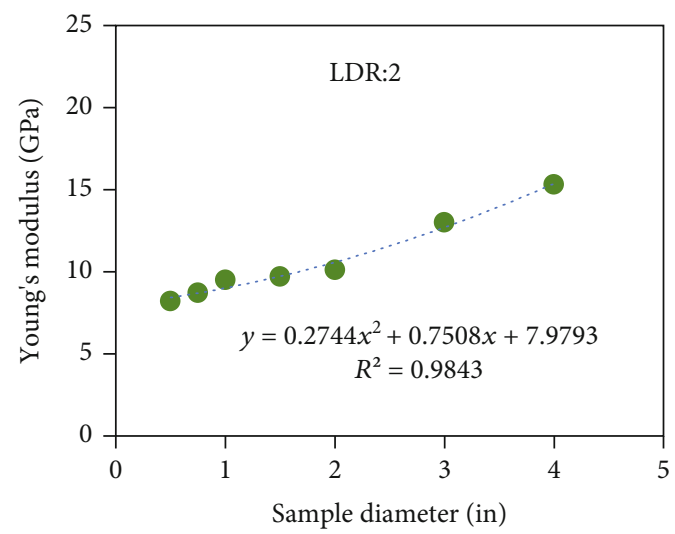

FIgURE 8: Effect of sample size on $E$.

and LDR 2.0; $\mathrm{EN}_{j}^{i}$ is normalized Young's modulus indicator of the sample with diameter $i$ and LDR $j ; \mathrm{SF}_{E}$ is Young's modulus standardizing factor; $v_{j}^{i}$ is Poisson's ratio of the sample with diameter $i$ and LDR $j ; v_{2}^{i}$ is Poisson's ratio of the sample with diameter $i$ and LDR 2.0; $v N_{j}^{i}$ is normalized Poisson's ratio indicator of the samples with diameter $i$ and $\mathrm{LDR} j ; \mathrm{SF}_{v}$ is Poisson's ratio standardizing factor; $K_{j}^{i}$ is the bulk modulus of the sample with diameter $i$ and LDR $j ; K_{2}^{i}$ 
TABLe 6: Effects of LDR on Poisson's ratio of Berea sandstones.

\begin{tabular}{|c|c|c|c|c|c|}
\hline LDR & $D$ (in) & $L$ (in) & $v$ & $v_{N}$ & $S F_{v}$ \\
\hline 1 & 0.75 & 0.75 & 0.315 & 0.95 & \multirow{6}{*}{0.89} \\
\hline 1 & 1 & 1 & 0.326 & 0.87 & \\
\hline 1 & 1.5 & 1.5 & 0.318 & 0.82 & \\
\hline 1 & 2 & 2 & 0.326 & 0.89 & \\
\hline 1 & 3 & 3 & 0.324 & 0.92 & \\
\hline 1 & 4 & 4 & 0.332 & 0.91 & \\
\hline 1.2 & 1 & 1.2 & 0.334 & 0.89 & \multirow{2}{*}{0.87} \\
\hline 1.2 & 1.5 & 1.8 & 0.328 & 0.84 & \\
\hline 1.3 & 0.75 & 1 & 0.372 & 1.12 & \multirow{3}{*}{1.04} \\
\hline 1.3 & 1.5 & 2 & 0.376 & 0.97 & \\
\hline 1.3 & 3 & 4 & 0.357 & 1.02 & \\
\hline 1.5 & 0.5 & 0.75 & 0.406 & 1.21 & \multirow{4}{*}{1.06} \\
\hline 1.5 & 1 & 1.5 & 0.399 & 1.06 & \\
\hline 1.5 & 2 & 3 & 0.367 & 1.01 & \\
\hline 1.5 & 4 & 6 & 0.355 & 0.98 & \\
\hline 1.6 & 0.75 & 1.2 & 0.367 & 1.11 & 1.11 \\
\hline 1.8 & 1 & 1.8 & 0.362 & 0.96 & 0.96 \\
\hline 2 & 0.5 & 1 & 0.336 & 1 & \multirow{7}{*}{1} \\
\hline 2 & 0.75 & 1.5 & 0.331 & 1 & \\
\hline 2 & 1 & 2 & 0.376 & 1 & \\
\hline 2 & 1.5 & 3 & 0.389 & 1 & \\
\hline 2 & 2 & 4 & 0.365 & 1 & \\
\hline 2 & 3 & 6 & 0.351 & 1 & \\
\hline 2 & 4 & 8 & 0.364 & 1 & \\
\hline 2.4 & 0.5 & 1.2 & 0.328 & 0.98 & \multirow{2}{*}{0.92} \\
\hline 2.4 & 0.75 & 1.8 & 0.286 & 0.86 & \\
\hline 2.5 & 4 & 10 & 0.368 & 1.01 & 1.01 \\
\hline 2.7 & 0.75 & 2 & 0.314 & 0.95 & \multirow{3}{*}{0.85} \\
\hline 2.7 & 1.5 & 4 & 0.389 & 1.00 & \\
\hline 2.7 & 3 & 8 & 0.208 & 0.59 & \\
\hline 3 & 0.5 & 1.5 & 0.261 & 0.78 & \multirow{3}{*}{0.80} \\
\hline 3 & 1 & 3 & 0.224 & 0.60 & \\
\hline 3 & 2 & 6 & 0.378 & 1.04 & \\
\hline 3.3 & 3 & 10 & 0.375 & 1.07 & 1.07 \\
\hline 4 & 1 & 4 & 0.378 & 1.01 & \multirow{3}{*}{0.79} \\
\hline 4 & 1.5 & 6 & 0.269 & 0.69 & \\
\hline 4 & 2 & 8 & 0.245 & 0.67 & \\
\hline 5 & 2 & 10 & 0.322 & 0.88 & 0.88 \\
\hline 5.3 & 1.5 & 8 & 0.231 & 0.59 & 0.59 \\
\hline 6 & 1 & 6 & 0.308 & 0.82 & 0.82 \\
\hline 6.7 & 1.5 & 10 & 0.222 & 0.57 & 0.57 \\
\hline
\end{tabular}

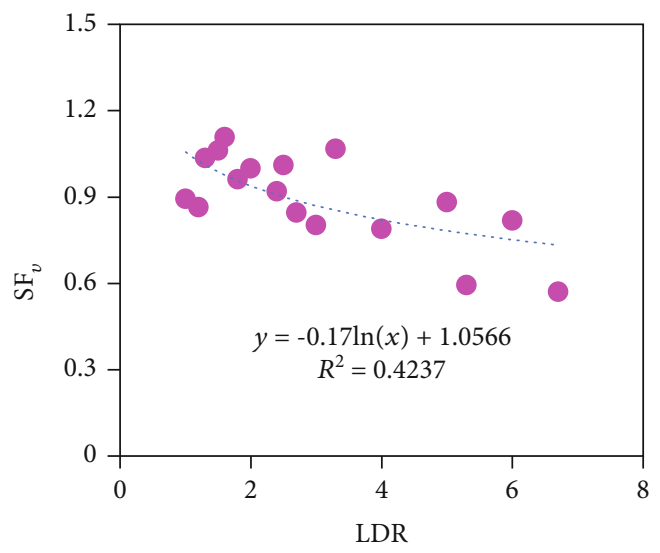

FIgURE 9: The relationship of LDR and $\mathrm{SF}_{v}$.

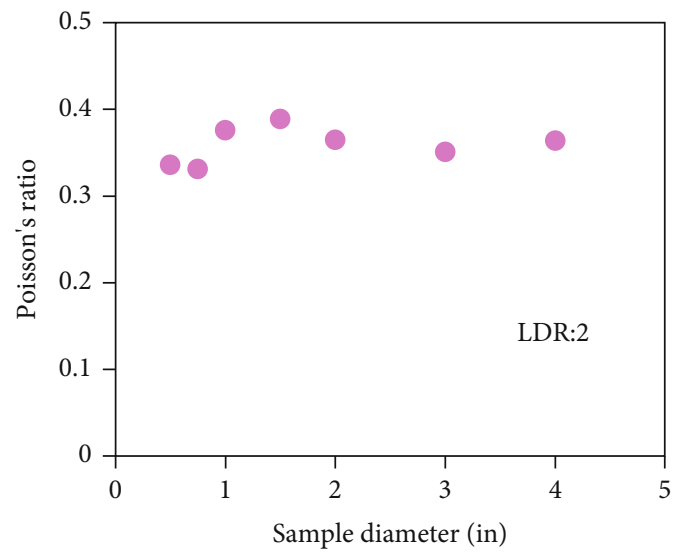

Figure 10: Effect of sample size on $v$.

is the bulk modulus of the sample with diameter $i$ and LDR $2.0 ; \mathrm{KN}_{j}^{i}$ is the normalized bulk modulus indicator of the sample with diameter $i$ and $\mathrm{LDR} j ; \mathrm{SF}_{K}$ is the bulk modulus standardizing factor; $G_{j}^{i}$ is the shear modulus of the sample with diameter $i$ and LDR $j$; $G_{2}^{i}$ is the shear modulus of the sample with diameter $i$ and LDR 2.0; $\mathrm{GN}_{j}^{i}$ is the normalized shear modulus indicator of the sample with diameter $i$ and LDR $j ; \mathrm{SF}_{G}$ is the shear modulus standardizing factor.

Poisson's ratio is a measure of the effect that when a material is compressed in one direction, the direction perpendicular to the compressive direction would usually expand. Poisson's ratio is dependent on the material and is valid in the material's elastic deformation region [26, 27]. Table 6 is the summary of Poisson's ratio of the tested Berea sandstone samples. According to the normalized results of this work, Poisson's ratio standardizing factor $\left(\mathrm{SF}_{v}\right)$ has negative relationship with LDR (Figure 9), which means that Poisson's ratio of the tested samples decreases with the increase of LDR. The relationship between LDR and Poisson's ratio is not linear (Table 5). Poisson's ratio standardizing factor for the tested Berea sandstone samples is between 0.57 and 1.11, which means 
TABLE 7: Effects of LDR on bulk modulus of Berea sandstones.

\begin{tabular}{|c|c|c|c|c|c|}
\hline LDR & $D$ (in) & $L$ (in) & $K(\mathrm{GPa})$ & $K_{N}$ & $\mathrm{SF}_{K}$ \\
\hline 1 & 0.75 & 0.75 & 7.1 & 0.83 & \multirow{6}{*}{0.78} \\
\hline 1 & 1 & 1 & 8.2 & 0.65 & \\
\hline 1 & 1.5 & 1.5 & 9.3 & 0.64 & \\
\hline 1 & 2 & 2 & 11.1 & 0.89 & \\
\hline 1 & 3 & 3 & 12.5 & 0.86 & \\
\hline 1 & 4 & 4 & 14.8 & 0.79 & \\
\hline 1.2 & 1 & 1.2 & 8.1 & 0.64 & \multirow{2}{*}{0.66} \\
\hline 1.2 & 1.5 & 1.8 & 9.9 & 0.68 & \\
\hline 1.3 & 0.75 & 1 & 9.5 & 1.11 & \multirow{3}{*}{1.04} \\
\hline 1.3 & 1.5 & 2 & 13.7 & 0.94 & \\
\hline 1.3 & 3 & 4 & 15.5 & 1.07 & \\
\hline 1.5 & 0.5 & 0.75 & 14.5 & 1.74 & \multirow{4}{*}{1.33} \\
\hline 1.5 & 1 & 1.5 & 21.1 & 1.65 & \\
\hline 1.5 & 2 & 3 & 14.9 & 1.20 & \\
\hline 1.5 & 4 & 6 & 13.9 & 0.74 & \\
\hline 1.6 & 0.75 & 1.2 & 10.4 & 1.21 & 1.21 \\
\hline 1.8 & 1 & 1.8 & 11.2 & 0.88 & 0.88 \\
\hline 2 & 0.5 & 1 & 8.3 & 1 & \multirow{7}{*}{1} \\
\hline 2 & 0.75 & 1.5 & 8.6 & 1 & \\
\hline 2 & 1 & 2 & 12.8 & 1 & \\
\hline 2 & 1.5 & 3 & 14.6 & 1 & \\
\hline 2 & 2 & 4 & 12.5 & 1 & \\
\hline 2 & 3 & 6 & 14.5 & 1 & \\
\hline 2 & 4 & 8 & 18.8 & 1 & \\
\hline 2.4 & 0.5 & 1.2 & 9.5 & 1.14 & \multirow{2}{*}{0.94} \\
\hline 2.4 & 0.75 & 1.8 & 6.4 & 0.74 & \\
\hline 2.5 & 4 & 10 & 19.9 & 1.06 & 1.06 \\
\hline 2.7 & 0.75 & 2 & 8.2 & 0.96 & \multirow{3}{*}{0.89} \\
\hline 2.7 & 1.5 & 4 & 18.0 & 1.24 & \\
\hline 2.7 & 3 & 8 & 7.0 & 0.48 & \\
\hline 3 & 0.5 & 1.5 & 6.6 & 0.79 & \multirow{3}{*}{0.86} \\
\hline 3 & 1 & 3 & 6.5 & 0.51 & \\
\hline 3 & 2 & 6 & 16.0 & 1.28 & \\
\hline 3.3 & 3 & 10 & 16.8 & 1.16 & 1.16 \\
\hline 4 & 1 & 4 & 12.7 & 0.99 & \multirow{3}{*}{0.78} \\
\hline 4 & 1.5 & 6 & 8.8 & 0.60 & \\
\hline 4 & 2 & 8 & 9.2 & 0.73 & \\
\hline 5 & 2 & 10 & 10.9 & 0.87 & 0.87 \\
\hline 5.3 & 1.5 & 8 & 6.4 & 0.44 & 0.44 \\
\hline 6 & 1 & 6 & 10.2 & 0.80 & 0.80 \\
\hline 6.7 & 1.5 & 10 & 6.7 & 0.46 & 0.46 \\
\hline
\end{tabular}

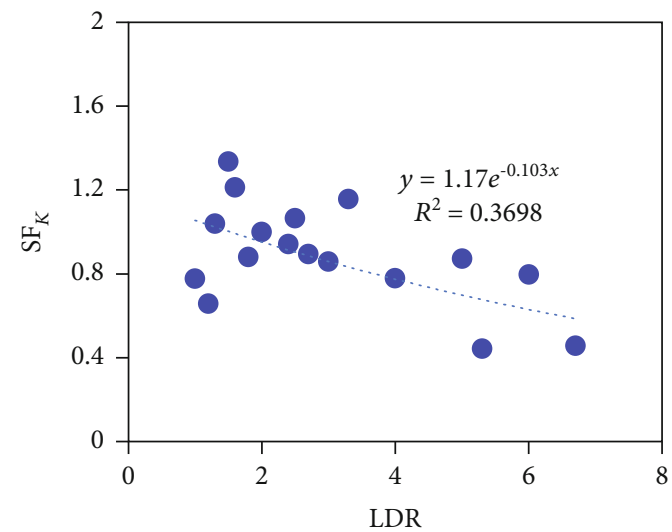

FIgURE 11: The relationship of LDR and $\mathrm{SF}_{K}$.

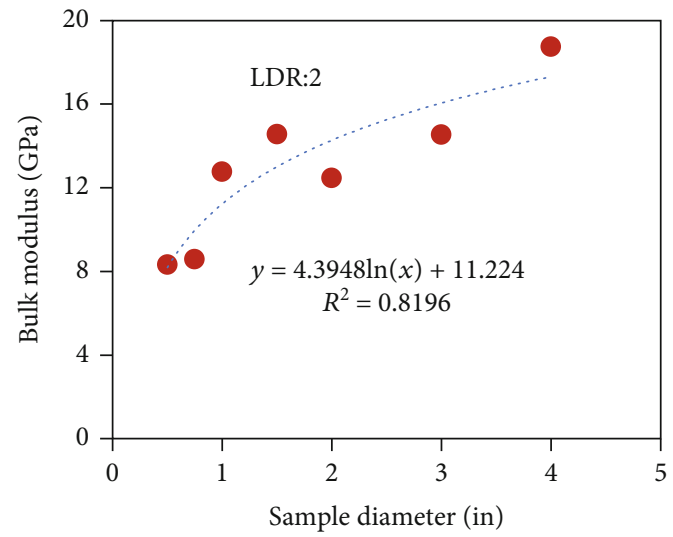

FIgURe 12: Effect of sample size on $K$.

the dramatic variation of Poisson's ratio caused by LDR changing from 1 to 6.7. From Figure 10, we can observe that there is no consistent positive or negative relationship between sample size and Poisson's ratio for LDR at 2 . Therefore, the relationship of sample size and Poisson's ratio is not apparent for the tested Berea sandstone samples in this study.

Table 7 is the summary of bulk modulus and the calculated $\mathrm{KN}$ and $\mathrm{SF}_{K}$ of the tested Berea sandstone samples. In order to study the LDR effect on bulk modulus, data normalization process was performed. According to the normalized results of this research, bulk modulus of Berea sandstone samples decreases with LDR increases, as shown in Figure 11. Because the correlation coefficient of the regression curve is only 0.37 (Table 5), the relationship between LDR and bulk modulus is not strong. But we can observe that bulk modulus standardizing factor $\left(\mathrm{SF}_{K}\right)$ varies between 0.44 and 1.33, which means that LDR changing from 1 to 6.7 can result in great variation of bulk modulus of the tested Berea sandstones. Figure 12 shows the bulk modulus increases with sample size increases with LDR at 2, which illustrates bulk modulus increases with the increase of sample size.

Table 8 is the summary of shear modulus and the calculated $\mathrm{GN}$ and $\mathrm{SF}_{G}$ of the tested Berea sandstone samples. 
TABLE 8: Effects of LDR on shear modulus of Berea sandstones.

\begin{tabular}{|c|c|c|c|c|c|}
\hline LDR & $D$ (in) & $L$ (in) & $G(\mathrm{GPa})$ & GN & SFG \\
\hline 1 & 0.75 & 0.75 & 3.0 & 0.92 & \multirow{6}{*}{1.03} \\
\hline 1 & 1 & 1 & 3.2 & 0.94 & \\
\hline 1 & 1.5 & 1.5 & 3.9 & 1.11 & \\
\hline 1 & 2 & 2 & 4.4 & 1.18 & \\
\hline 1 & 3 & 3 & 5.0 & 1.04 & \\
\hline 1 & 4 & 4 & 5.6 & 1.00 & \\
\hline 1.2 & 1 & 1.2 & 3.0 & 0.88 & \multirow{2}{*}{0.99} \\
\hline 1.2 & 1.5 & 1.8 & 3.8 & 1.10 & \\
\hline 1.3 & 0.75 & 1 & 2.7 & 0.81 & \multirow{3}{*}{0.96} \\
\hline 1.3 & 1.5 & 2 & 3.7 & 1.06 & \\
\hline 1.3 & 3 & 4 & 4.9 & 1.02 & \\
\hline 1.5 & 0.5 & 0.75 & 2.9 & 0.95 & \multirow{4}{*}{1.06} \\
\hline 1.5 & 1 & 1.5 & 4.6 & 1.33 & \\
\hline 1.5 & 2 & 3 & 4.4 & 1.18 & \\
\hline 1.5 & 4 & 6 & 4.5 & 0.80 & \\
\hline 1.6 & 0.75 & 1.2 & 3.0 & 0.93 & 0.93 \\
\hline 1.8 & 1 & 1.8 & 3.4 & 0.99 & 0.99 \\
\hline 2 & 0.5 & 1 & 3.1 & 1 & \multirow{7}{*}{1} \\
\hline 2 & 0.75 & 1.5 & 3.3 & 1 & \\
\hline 2 & 1 & 2 & 3.5 & 1 & \\
\hline 2 & 1.5 & 3 & 3.5 & 1 & \\
\hline 2 & 2 & 4 & 3.7 & 1 & \\
\hline 2 & 3 & 6 & 4.8 & 1 & \\
\hline 2 & 4 & 8 & 5.6 & 1 & \\
\hline 2.4 & 0.5 & 1.2 & 3.7 & 1.20 & \multirow{2}{*}{1.09} \\
\hline 2.4 & 0.75 & 1.8 & 3.2 & 0.98 & \\
\hline 2.5 & 4 & 10 & 5.8 & 1.03 & 1.03 \\
\hline 2.7 & 0.75 & 2 & 3.5 & 1.07 & \multirow{3}{*}{1.12} \\
\hline 2.7 & 1.5 & 4 & 4.3 & 1.24 & \\
\hline 2.7 & 3 & 8 & 5.1 & 1.06 & \\
\hline 3 & 0.5 & 1.5 & 3.7 & 1.21 & \multirow{3}{*}{1.21} \\
\hline 3 & 1 & 3 & 4.4 & 1.27 & \\
\hline 3 & 2 & 6 & 4.2 & 1.15 & \\
\hline 3.3 & 3 & 10 & 4.6 & 0.95 & 0.95 \\
\hline 4 & 1 & 4 & 3.4 & 0.98 & \multirow{3}{*}{1.29} \\
\hline 4 & 1.5 & 6 & 4.8 & 1.38 & \\
\hline 4 & 2 & 8 & 5.6 & 1.52 & \\
\hline 5 & 2 & 10 & 4.4 & 1.19 & 1.19 \\
\hline 5.3 & 1.5 & 8 & 4.2 & 1.21 & 1.21 \\
\hline 6 & 1 & 6 & 4.5 & 1.30 & 1.30 \\
\hline 6.7 & 1.5 & 10 & 4.5 & 1.30 & 1.30 \\
\hline
\end{tabular}

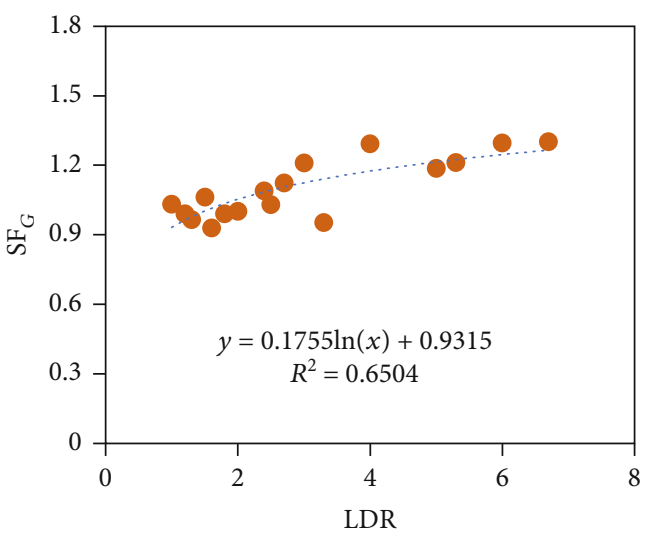

FIgURE 13: The relationship of LDR and $\mathrm{SF}_{G}$.

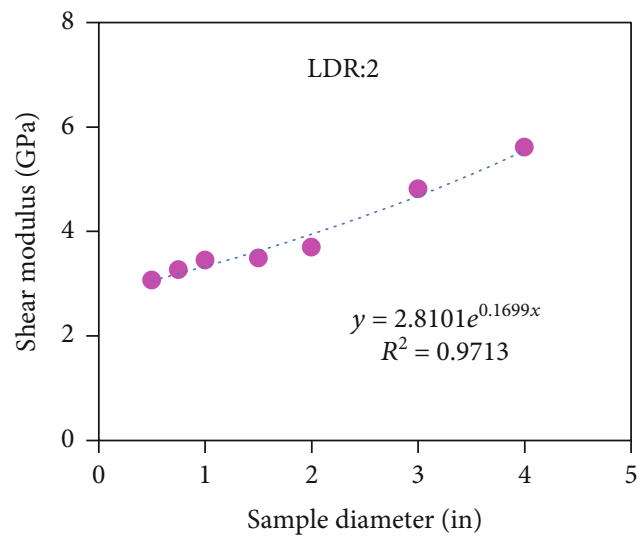

FIgURE 14: Effect of sample size on $G$.

According to the normalized test results, shear modulus of Berea sandstone samples increases with LDR increases (Figure 13). From Figure 13, we can observe that shear modulus standardizing factor $\left(\mathrm{SF}_{G}\right)$ varies between 0.93 and 1.3, which means that LDR change from 1 to 6.7 can result in $-10 \%$ to $+30 \%$ variation of shear modulus of the tested Berea sandstone samples. Figure 14 shows the shear modulus increases with sample size increases with LDR at 2, which illustrates the positive relationship of shear modulus and sample size.

4.3. Failure Mode Analysis. In this study, failure modes of 41 Berea sandstone samples under uniaxial compression tests were investigated. Based on the test results, the principal failure modes of the Berea sandstone samples are axial splitting and shear failure. We can also observe that the failure modes are affected by LDR. When LDR is less than 2, samples exhibited axial splitting. When LDR is larger than 2, samples showed shear failure. For samples with LDR equals to 2, some samples show shear failure, while some samples exhibit axial splitting (Figure 15). The test results of Berea sandstone samples illustrated that under uniaxial compression tests, stocky samples (LDR $<2$ ) tend to show axial splitting, while slender samples $(\mathrm{LDR}>2)$ tend to go shear failure. Figures 16 and 17 show 


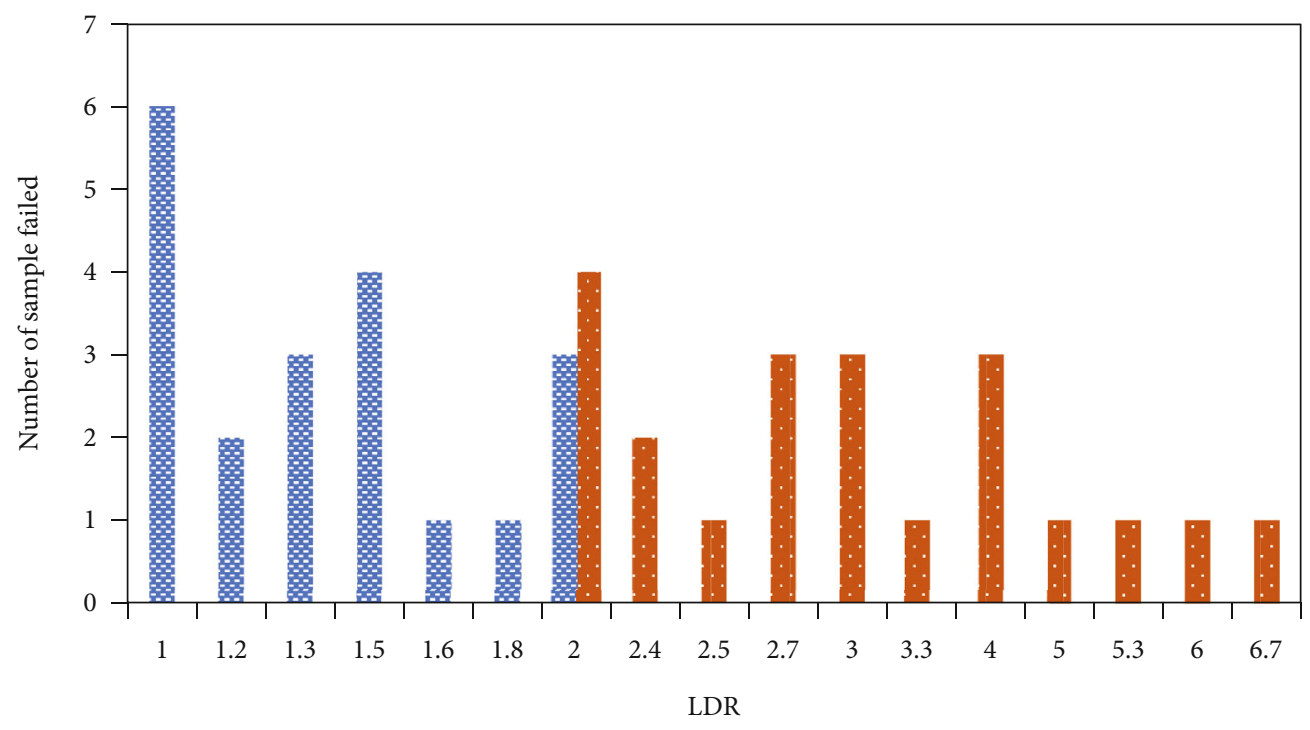

풍 Axial splitting

anear failure

FIgURE 15: The failure modes of Berea sandstone samples.

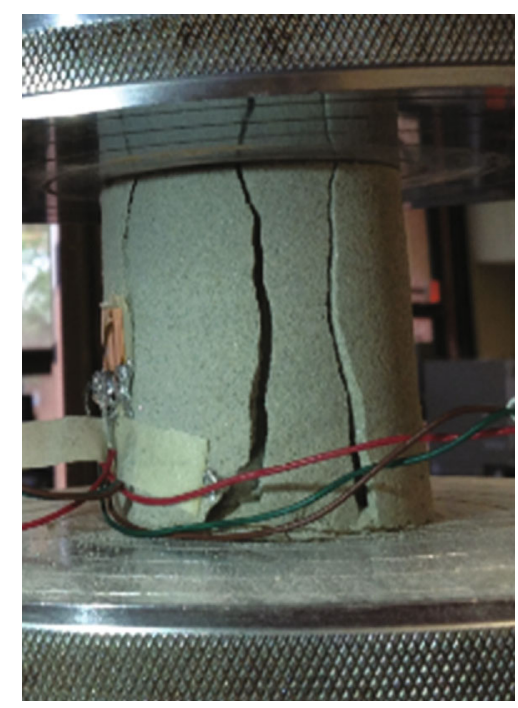

Figure 16: Axial splitting failure with 2 inches in diameter and 2 inches in length.

the axial splitting failure mode and shear broken failure mode of the tested Berea sandstone samples.

\section{Conclusions}

Experimental investigation has been conducted on 41 Berea sandstone samples to study the scale effects on the mechanical behaviors. According to the test results, the geometry of core samples has dramatic impacts on rock mechanical properties. The specific conclusions are listed below.
(1) UCS of Berea sandstone decreases with LDR increases. The UCS standardizing factor is between 0.71 and 1.17 , which means $-30 \%$ to $+20 \%$ variation of UCS with LDR changing from 1 to 6.7. UCS of the tested samples exhibits positive relationship with sample size

(2) Young's modulus slightly increases with the increase of LDR. When LDR changes from 1 to 6.7, Young's modulus is in $-5 \%$ to $+23 \%$ variation. At the same LDR, Young's modulus of Berea sandstone increases with sample size increases

(3) Poisson's ratio decreases significantly with LDR increases. The standardizing factor of Poisson's ratio is between 0.57 and 1.11, which means LDR has a dramatic influence on Poisson's ratio. Sample size effect on Poisson's ratio is not apparent in this study

(4) Bulk modulus of Berea sandstone samples decreases with LDR increases, while shear modulus increases with LDR increases. Both bulk modulus and shear modulus increase with the increase of sample size

(5) Failure modes of the tested 41 Berea sandstone samples are analyzed. The principal failure modes are axial splitting and shear failure, which are affected by LDR. Stocky samples (LDR $<2$ ) tend to show axial splitting, while slender samples (LDR $>2$ ) tend to go shear failure

\section{Nomenclature}

UCS: Uniaxial compressive strength, $\mathrm{MPa}$

E: $\quad$ Young's modulus, GPa 


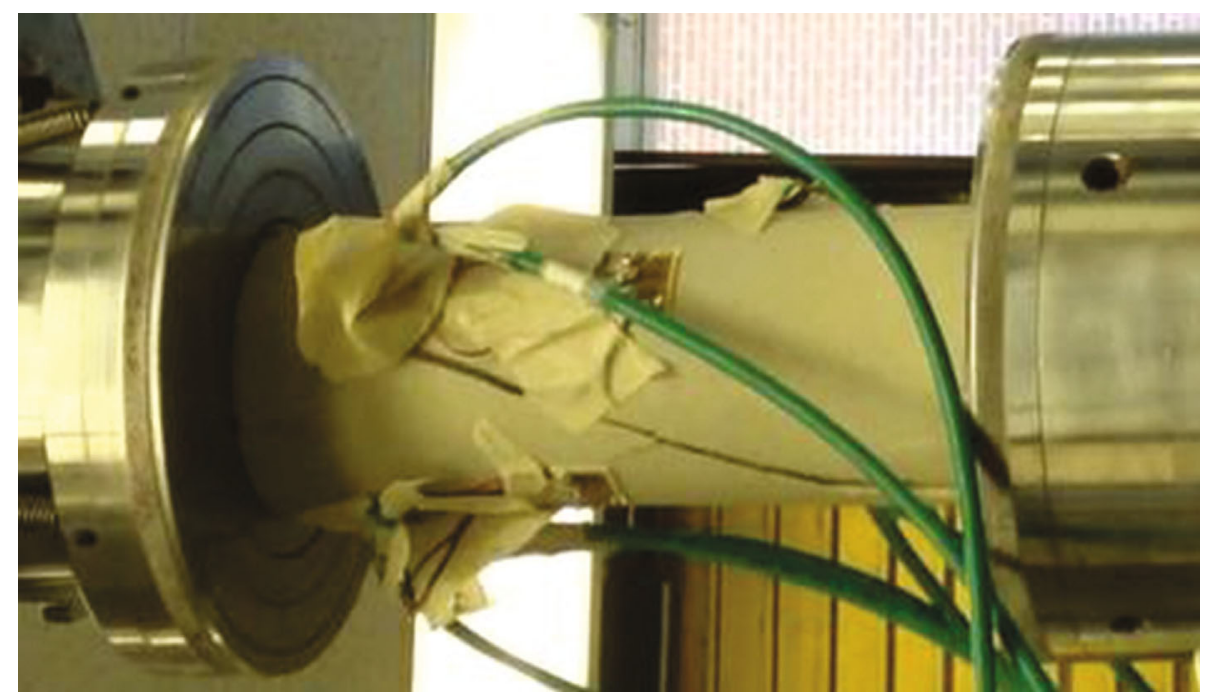

FIgURE 17: Shear broken failure with 3 inches in diameter and 8 inches in length.

v: Poisson's ratio

D: $\quad$ Diameter, inch

L: $\quad$ Length, inch

LDR: Length to diameter ratio

ASTM: American Society for Testing and Materials

ISRM: International Society of Rock Mechanics

$\sigma_{u}: \quad$ Uniaxial compressive strength (UCS), $\mathrm{MPa}$

$P: \quad$ Failure load, $\mathrm{MPa}$

A: $\quad$ Cross-sectional area, $\mathrm{cm}^{2}$

$\varepsilon_{y}: \quad$ Lateral strain

$\varepsilon_{x}$ : $\quad$ Longitudinal strain

$\mathrm{UCS}_{j}^{i}$ : $\quad$ UCS of sample with diameter $i$ and LDR $j$

$\mathrm{UCS}_{2}{ }_{2}$ : $\quad$ UCS of the test samples with diameter $i$ and LDR 2

$\mathrm{UCSN}_{j}^{i}$ : Normalized UCS indicator of samples with diameter $i$ and LDR $j$

$\mathrm{SF}_{\mathrm{UCS}}$ : UCS standardizing factor

$\mathrm{SF}_{\mathrm{UCS} j}$ : UCS standardizing factor with $\mathrm{LDR} j$

$E_{j}^{i}$ : $\quad$ Young's modulus of the sample with diameter $i$ and $\operatorname{LDR} j$

$E_{2}^{i}$ : $\quad$ Young's modulus of the sample with diameter $i$ and LDR 2

$\mathrm{EN}_{j}^{i}$ : $\quad$ Normalized Young's modulus indicator of the sample with diameter $i$ and LDR $j$

$\mathrm{SF}_{E}$ : Young's modulus standardizing factor

$v_{j}^{i}: \quad$ Poisson's ratio of the sample with diameter $i$ and LDR $j$

$v_{2}^{i}$ : $\quad$ Poisson's ratio of the sample with diameter $i$ and LDR 2

$v N_{j}^{i}$ : Normalized Poisson's ratio indicator of the samples with diameter $i$ and LDR $j$

$\mathrm{SF}_{v}$ : Poisson's ratio standardizing factor

$K_{j}^{i}$ : $\quad$ Bulk modulus of the sample with diameter $i$ and LDR $j$

$K_{2}^{i}$ : $\quad$ Bulk modulus of the sample with diameter $i$ and LDR 2

$\mathrm{KN}_{j}^{i}$ : $\quad$ Normalized bulk modulus indicator of the sample with diameter $i$ and LDR $j$

$\mathrm{SF}_{K}$ : Bulk modulus standardizing factor
$G_{j}^{i}$ : $\quad$ Shear modulus of the sample with diameter $i$ and LDR $j$

$G_{2}^{i}$ : $\quad$ Shear modulus of the sample with diameter $i$ and LDR 2

$\mathrm{GN}_{j}^{i}$ : $\quad$ Normalized shear modulus indicator of the sample with diameter $i$ and LDR $j$

$\mathrm{SF}_{G}$ : Shear modulus standardizing factor.

\section{Data Availability}

The data used to support the findings of this study are included within the article.

\section{Conflicts of Interest}

The authors declare that they have no conflicts of interest.

\section{Acknowledgments}

This research was supported by the National Science Foundation of China (No. 51834005), by the Innovation Fund of China National Petroleum Corporation (2019D-50070201), by the National Natural Science Foundation Projects of Shanxi Provincial (Program No. 2020JM-534), and by the Science Foundation of China University of Petroleum, Beijing (No. 2462017YJRC041 and No. 2462020XKBH013). The authors appreciate Dr. Bitao Lai for the support and guidance on this paper.

\section{References}

[1] D. N. Dewhurst, A. F. Siggins, U. Kuila, M. B. Clennell, M. D. Raven, and H. M. Nordgard-Bolas, "Elastic, geomechanical and petrophysical properties of shales," in Paper ARME 08208 presented at the 42nd US Rock Mechanics Symposium and 2nd U.S.-Canada Rock Mechanics Symposium, San Francisco, USA, 2008.

[2] V. Dokhani, M. J. Yu, and B. Bloys, "A wellbore stability model for shale formations: accounting for strength anisotropy and 
fluid induced instability," Journal of Natural Gas Science and Engineering, vol. 1, no. 32, pp. 174-184, 2016.

[3] Y. W. Li, M. Long, J. Z. Tang, M. Chen, and X. F. Fu, "A hydraulic fracture height mathematical model considering the influence of plastic region at fracture tip," Petroleum Exploration and Development, vol. 47, no. 1, pp. 184-195, 2020.

[4] Y. W. Li, S. Yang, W. C. Zhao, W. Li, and J. Zhang, "Experimental of hydraulic fracture propagation using fixed-point multistage fracturing in a vertical well in tight sandstone reservoir," Journal of Petroleum Science and Engineering, vol. 171, pp. 704-713, 2018.

[5] S. H. Lin and B. T. Lai, "Experimental investigation of water saturation effects on Barnett shale's geomechanical behaviors," in Paper SPE-166234-MS presented at SPE Annual Technical Conference and Exhibition, New Orleans, Louisiana, USA, 2013.

[6] Z. W. Wu, C. Cui, G. Lv, S. Bing, and G. Cao, “A multi-linear transient pressure model for multistage fractured horizontal well in tight oil reservoirs with considering threshold pressure gradient and stress sensitivity," Journal of Petroleum Science and Engineering, vol. 172, pp. 839-854, 2019.

[7] Z. W. Wu, C. Cui, Y. Ye, X. Cheng, and J. Trivedi, “A fractal model for quantitative evaluating the effects of spontaneous imbibition and displacement on the recovery of tight reservoirs," Petroleum Science and Engineering, vol. 198, p. 108120, 2021.

[8] A. P. D. Cunha, "Scale effects in the determination of mechanical properties of joints and rock masses," in Paper ISRM7CONGRESS-1991-062 presented for the 7th ISRM CONGRESS, Aachen, Germany, 1991.

[9] Z. T. Bieniawski, "The effect of specimen size on compressive strength of coal," International Journal of Rock Mechanics and Mining Sciences, vol. 5, no. 4, pp. 325-335, 1968.

[10] R. Jackson and J. S. O. Lau, "The effect of specimen size on the laboratory mechanical properties of Lac du Bonnet grey granite," in Scale Effects in Rock Masses, P. Cunha, Ed., pp. 165174, Balkema, 1990.

[11] K. Thuro, R. J. Plinninger, S. Zah, and S. Schutz, "Scale effect in rock strength properties," Part 1: Unconfined Compressive Test and Brazilian Test. Rock Mechanics- a Challenge for Society, 2001.

[12] Y. S. Lou and Y. Q. Jin, Rock Mechanics and Petroleum Engineering, Petroleum industry Press, Beijing China, 2006.

[13] ISRM, $2^{\text {nd }}$ Workshop on Petroleum Geomechanics Testing: Rock Physics Methods for Determining Mechanical Properties, The Westin Market Street, San Francisco, 2013.

[14] M. Forbes, H. Masoumi, S. Saydam, and P. Hagan, "Investigation into the effect of length to diameter ratio on the point load strength index of Gosford sandstone," in The 49th US Rock Mechanics/Geomechanics Symposium, San Francisco, CA, USA, 2015.

[15] M. John, The influence of length to diameter ratio on rock properties in uniaxial compression: a contribution to standardization in rock mechanics testing. Rep $S$ AFr CSIR No. ME1083/5, 1972.

[16] K. Mogi, "Some precise measurements of fracture strength of rocks under uniform compressive stress," Felsmechanik und Ingenieurgeologie, vol. 4, pp. 41-55, 1966.

[17] K. Mogi, Experimental Rock Mechanics, Taylor \& Francis, London, 2007.
[18] A. P. Dirige and J. Archibald, "The effects of geometry on the uniaxial compressive strength properties of intact rock core specimens," in Paper ARMA-06-1016 presented for the 41st U.S. symposium on rock mechanics (USRMS), Golden, Colorado, 2006.

[19] E. Tuncay and N. Hasancebi, "The effect of length to diameter ratio of test specimens on the uniaxial compressive strength of rock," Bulletin of Engineering Geology and the Environment, vol. 68, no. 4, pp. 491-497, 2009.

[20] U. Prasad, D. A. Moronkeji, R. Shouse, D. A. Funes, and C. Wolfe, "Length-to-diameter ratio (L/D) of rotary sidewall cores and its implications for estimating compressive strengths (UCS or CCS) in petroleum geomechanics," in 53rd U.S. rock mechanics/geomechanics symposium, New York City, New York, 2019.

[21] E. Hoek and E. T. Brown, "Underground excavations in rock," in Institution of Mining and Metallurgy, p. 527, Stephen Austin and Sons Ltd., Hertford, London, 1980.

[22] A. B. Hawkins, "Aspects of rock strength," Bulletin of Engineering Geology and the Environment, vol. 57, no. 1, pp. 1730, 1998.

[23] H. Masoumi and K. J. Douglas, "Experimental study of size effect of rock on UCS and point load tests," in Paper ARMA 12-215 presented for the 46th US Rock Mechanics/Geomechanics Symposium, Chicage, IL, USA, 2012.

[24] B. T. Lai, H. Li, J. L. Zhang, D. Jacobi, and D. Georgi, "Water content effects on dynamic elastic properties of organic-rich shale," Society of Petroleum Engineers, SPE-175040-PA, vol. 21, no. 2, pp. 635-647, 2015.

[25] H. Li, B. T. Lai, and S. H. Lin, "Shale mechanical properties influence factors overview and experimental investigation on water content effects," Journal of Sustainable Energy and Engineering, vol. 3, no. 4, pp. 275-298, 2016.

[26] O. M. Akrad, J. L. Miskimins, and M. Prasad, "The effects of fracturing fluids on shale rock mechanical properties and proppant embedment," in Paper SPE-146658-MS presented at SPE Annual Technical Conference and Exhibition, Denver, Colorado, USA, 2011.

[27] J. He, K. Ling, X. Wu, P. Pei, and H. Pu, "Static and dynamic elastic moduli of Bakken formation," in International Petroleum Technology Conference, Beijing, China, 2019. 